\title{
Reflexión bioética sobre trasplantes de pulmón
}

\author{
LIBIA LARA C.* y ALBERTO ROJAS O.**
}

Bioethics reflection about lung transplant

Despite a substantial improvement in organ transplant techniques and rejections methods, Chile still exhibits an apparent lack of adequate increase of lung transplants. In particular, despite the presence of precise indicactions of lung transplant, the problem of limited donors is a very difficult reality for the receptors. In this work, we offer a comparison amongst Chile and Spain, with special emphasis on bioethical aspects of this process.

Key words: Transplant, respiratory organs, bioethics.

\section{Resumen}

A pesar de los avances que ha experimentado la técnica de los trasplantes de órganos y la mejora en manejo del rechazo, en nuestro país no se advierte un crecimiento adecuado a las necesidades de los trasplantes del sistema respiratorio requeridos. Si bien existen indicaciones precisas de trasplante pulmonar, el problema de la escasez de donantes es una dificultad concreta para los enfermos. Se revisa y compara nuestra situación con la de España y se analizan algunos aspectos bioéticos que surgen de este proceso.

Palabras clave: Trasplante, sistema respiratorio, bioética.

\section{Introducción}

El trasplante de órganos entre seres humanos es una técnica relativamente nueva en medicina, en la cual se implanta un órgano sólido o tejido procedente de un donante vivo o cadáver a un receptor. Constituye uno de los exponentes más significativos del progreso científico de la biología actual, optimizado gracias a las técnicas de conservación de vísceras por un lado y al desarrollo de medicamentos inmunosupresores, como la ciclosporina, por otro, que permiten una prolongada sobrevivencia del órgano trasplantado ${ }^{1}$.

A pesar que esta actividad ha ido creciendo a lo largo de los años, tal como veremos más adelante, aún no es suficiente, y faltan, en algunos casos en forma dramática, los órganos necesarios para muchos enfermos, particularmente del sistema respiratorio. Sin embargo, la generalización de la técnica ha hecho que la gama de posibilidades y experiencia en trasplante de órganos sólidos hoy abarque, además de pulmón, corazón, páncreas, hígado, riñón e intestino, convirtiéndose en una real alternativa para pacientes con enfermedad avanzada, terminales o con compromiso irreversible de la función hepática, cardiaca o pulmonar, quienes ya no disponen de otra medida terapéutica adecuada.

Por otra parte, la esperanza de vida en este tipo de pacientes es relativamente breve, por lo que, independientemente de los esfuerzos médicos y de la angustia que ello representa, muchos de ellos fallecen esperando el órgano que pudo salvar sus vidas.

Los buenos resultados conseguidos hoy gracias a las mejoras en las técnicas quirúrgicas, los métodos de inmunosupresión en el receptor y en los cuidados pre y postoperatorios, han contribuido a la proliferación de los programas de trasplantes, haciendo que aumente de forma importante el número de potenciales receptores $\mathrm{y}$, por tanto, la demanda de órganos, siendo actualmente la falta

\footnotetext{
* Psicóloga. Facultad de Medicina, Universidad Andrés Bello (UNAB), sede Viña del Mar, (c) Ph D Bioética Universidad Católica San Antonio de Murcia, España.

** Neumólogo, Facultad de Medicina, Universidad Andrés Bello (UNAB), Sede Viña del Mar.
} 
de donantes la que pone trabas al desarrollo de los trasplantes ${ }^{2}$.

\section{Desarrollo}

El trasplante de pulmón, actualmente es la última opción terapéutica aceptada para algunas enfermedades pulmonares no neoplásicas que alcanzan un daño avanzado e irreversible debido a numerosos factores, pero principalmente, progresión de la enfermedad de base y sus complicaciones. Al momento de proponer un paciente respiratorio para trasplante, la sobrevida no debe superar los dos años, planteado el diagnóstico por expertos. Actualmente, este procedimiento está avalado con la realización de más de 25.000 trasplantes pulmonares en todo el mundo ${ }^{3}$. Por ejemplo, en España, país referente en materia de donación-trasplantes, se han realizado 3.225 trasplantes pulmonares desde el año 1990 hasta 2013, lo que representa alrededor del 6\% del total mundial. La indicación más frecuente para los adultos en España es el enfisema/Enfermedad Pulmonar Obstructiva Crónica (EPOC), seguido de la fibrosis pulmonar idiopática. Entre ambas suponen más del $60 \%$ del total de las indicaciones. El tipo de procedimiento varía en función de la indicación del trasplante, siendo de tipo bilateral para la mayoría de los casos de fibrosis quística, lo que constituyó el $100 \%$ de los casos en 2009 y 2010 . El trasplante unilateral predomina en los pacientes con fibrosis pulmonar, aunque parece ir aumentando la realización de trasplantes bilaterales en los dos últimos años. En el caso de enfisema/EPOC el tipo de trasplante es casi el $50 \%$ para cada tipo de procedimiento 4 .

"La limitación de los recursos y, sobre todo, la escasez de donantes, nos obliga a evaluar este procedimiento por su eficiencia, además de por su eficacia. En el caso del pulmón, para saber si nuestro proceder es eficiente, es fundamental evaluar sus riesgos y los resultados a corto $y$ largo plazo en las diferentes situaciones. El candidato a trasplante pulmonar es un paciente grave e irreversiblemente enfermo que presenta un equilibrio inestable. En España, la media del tiempo de espera para el procedimiento está en torno a los 90 días, durante los cuales el paciente puede presentar una descompensación de su enfermedad de base y requerir su ingreso en una unidad de cuidados intensivos e incluso soporte ventilatorio. En esta situación la mortalidad es muy elevada, próxima al $100 \%$ si no se supera el proceso en pocos días. El riesgo de muerte súbita es también muy elevado entre los pacientes con hipertensión pulmonar primaria severa y rebelde al tratamiento"s.

Por otra parte, la principal ventaja del trasplante bipulmonar apunta a "que el manejo postoperatorio resulta más sencillo, al observarse una menor lesión de reperfusión que en el trasplante unipulmonar. Además, existe una mayor reserva pulmonar cuando aparece la bronquiolitis obliterante. A largo plazo, la ventaja más importante del trasplante bipulmonar sería una supervivencia mayor a la del unipulmonar"6.

La culminación exitosa de un proceso de esta naturaleza no es tarea fácil, ya que influyen variados factores como histocompatibilidad, lista de espera, capacidad de procuración, esquemas dispuestos para el transporte de órganos, factores geográficos, equipos médico-quirúrgicos organizados y centros dedicados a trasplante, costos globales económicos, entre otros.

Si se toma como ejemplo el modelo español, con vasta experiencia en un programa consolidado de trasplantes, se advertirá las grandes diferencias con nuestro país, con 3.225 trasplantes de pulmón y 80 de corazón/pulmón ${ }^{7}$, hasta 2013, cifras muy por encima de nuestra realidad. Se debe considerar que el tamaño de la población de España es considerablemente mayor que el de la población de Chile, de manera que para hacer comparaciones entre ambos países se deberían aplicar tasas.

En Chile, durante el año 2013 se efectuaron 31 trasplantes pulmonares, 19 de ellos pertenecientes al sector FONASA y 12 a ISAPRE. En el Hospital del Tórax, se realizaron 18 trasplantes de los 31 realizados en total ${ }^{8}$. Comparativamente, en España se realizaron en el mismo año, 285 trasplantes pulmonares ${ }^{7}$ (Figura 1a).

En cuanto a la donación de órganos, las cifras son elocuentes en valores absolutos: en 2013 hubo 1.655 donantes en España ${ }^{9}$, mientras que en Chile, los donantes fueron apenas 103 personas $^{10}$. Sin embargo, podemos comparar la tasa de donaciones en Chile y España (Figura 1b), las cuales son 5,9 pmp (por millón de población) versus 35,3 pmp respectivamente ${ }^{11}$.

Estos datos son actuales, su evolución se aprecia en la serie temporal, de trasplantes pulmonares en Chile y España (Figura 1a) y en el número de donantes de órganos por millón de habitantes en ambos países entre 1998 y 2013 (Figura 1b).

Una consecuencia directa de esta situación es que actualmente la lista de espera en Chile asciende a 1.370 pacientes, y de ellos, 45 están esperando un trasplante pulmonar ${ }^{8}$. En España el primero de enero del año 2013 se encontraban en lista de espera para trasplante de pulmón 204 

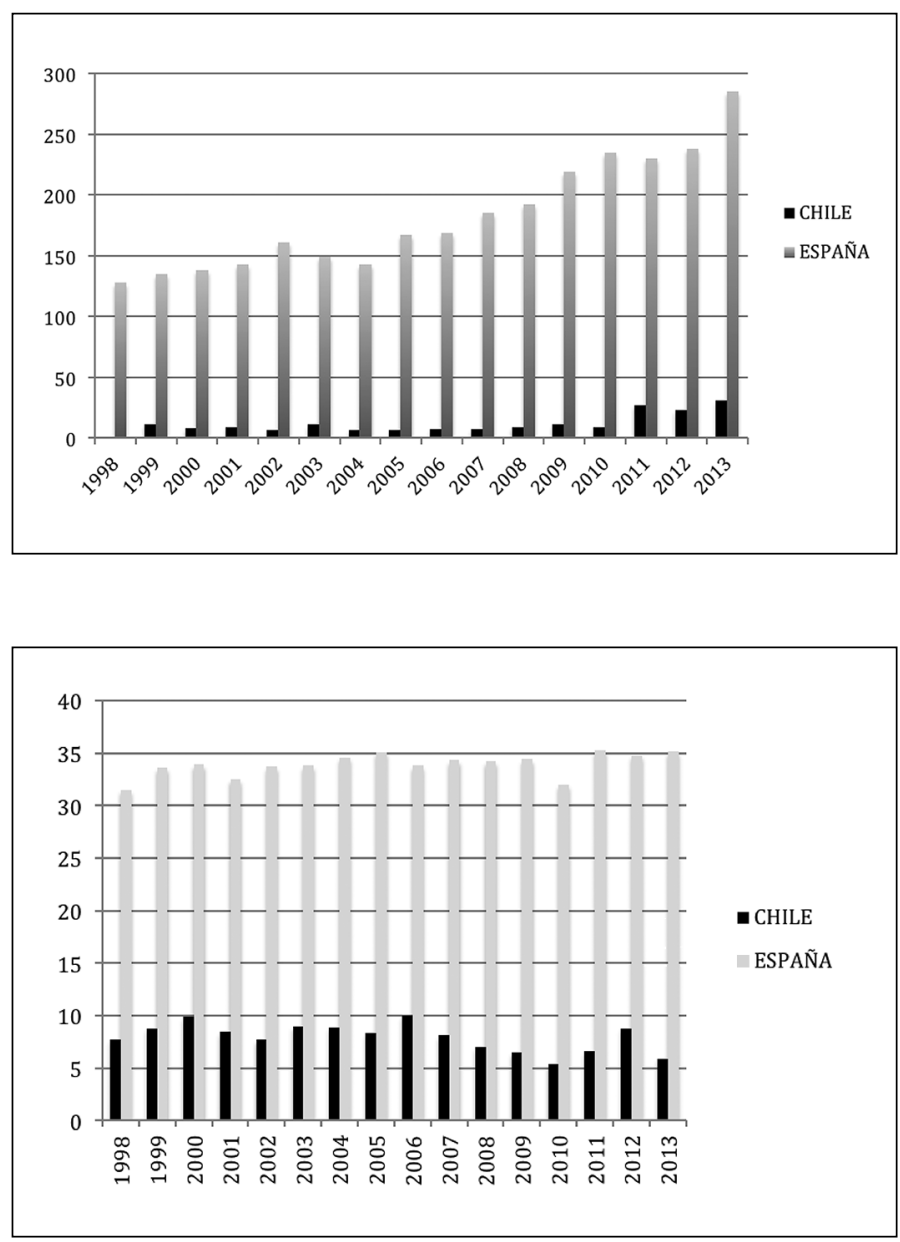

Figura 1a. Número de trasplantes pulmonares realizados en Chile y España desde 1998 hasta 2013. Las cifras de la ordenada representan el número de traplantes. Fuente: Organización Nacional de Trasplante $(\mathrm{ONT})^{7}$ y Corporación Nacional de Fomento de Trasplante ${ }^{8}$.

Figura 1b. Número de donantes de órganos por millón de población en Chile y España, desde 1998 hasta 2013. En la ordenada se representa el número de donantes en Chile (columnas negras) y en España (columnas grises). Fuente: Organización Nacional de Trasplante $(\mathrm{ONT})^{7}$ y Corporación Nacional de Fomento de Trasplante ${ }^{8}$.

pacientes. Durante este año se incluyeron 371 lo que supone un total de 575 pacientes en lista durante el año 2013. Se excluyeron de la lista 31 pacientes y fallecieron 22, situándose la mortalidad global en un 3,8\%. Al final de 2013 quedaban 237 receptores en lista para recibir trasplante pulmonar (Figura 2) ${ }^{9}$.

Debe destacarse el hecho que España es el país con mayor tasa de donación de toda Europa, con 35,3 pmp en 2013, lo que no significa que sea el país en el que más trasplantes se realizan. Actualmente tal país es Noruega con 92,8 pmp, seguido de España (88,8 pmp).

En el contexto latinoamericano, encabeza la lista de donaciones Uruguay, con 17,1 pmp, seguido de Argentina con 13,7. En Chile, la cifra es $5,9 \mathrm{pmp}$. Sin embargo, nuestro país, es el que exhibe la mayor tasa de trasplantes pulmonares en 2013, con 1,8 pmp, seguido de Argentina con $0,9 \mathrm{pmp}$. En lo referente al total de trasplantes de órganos por país, la lista la encabeza México con 48,5 pmp, seguido de Argentina (42,7 pmp), Uruguay (42,6 pmp), y Chile con 21,4 pmp ${ }^{11}$.

\section{Aspectos bioéticos}

El proceso de donación-trasplante es complejo y siempre cambiante. Más allá de los dos participantes involucrados principales, donante y receptor, está el contexto médico, también sujeto a dificultades y aspectos de organización y costos que superan el ámbito de esta reflexión. Igualmente importante durante todo el proceso que lleva la espera de un órgano, es la familia del enfermo, la que debe tolerar el sufrimiento que significa la situación biográfica, y vivir la angustia de observar el deterioro de su ser querido, así como sobrellevar la mayoría de las veces un alto impacto económico, dado lo costoso de todo el proceso de trasplante. No pocas veces, lamentablemente, el éxito es esquivo a su tesón y compañía. Resultados negativos en estos casos, no sólo deterioran la moral familiar del afectado, sino que son motivos de desesperanza para el resto de candidatos a la técnica. En este sentido, no puede desconocerse el impacto que esto provoca en la opinión pública, además lamentablemente 


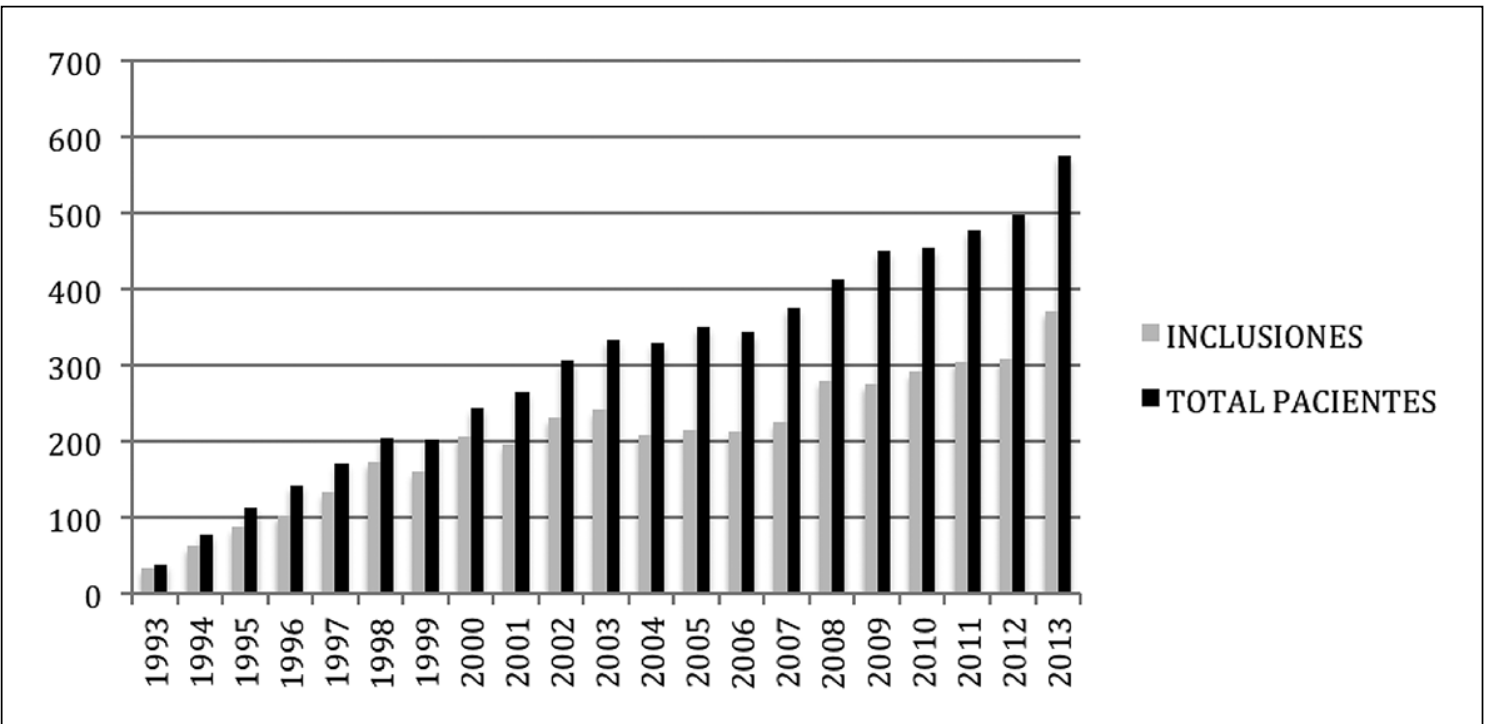

Figura 2. Evolución lista de espera de trasplante pulmonar: Inclusiones y total de pacientes. España 1993-2013. Las cifras de la ordenada del gráfico representan el número de pacientes. Fuente: Memoria trasplante pulmonar 2013. Organización Nacional de Trasplantes (ONT).

no siempre, la cobertura mediática resulta ser ponderada.

Sin embargo, existe otro aspecto en la humanidad que supone este proceso, tal vez mucho más conmovedor que el anterior. Nos referimos a la familia del donante, en quien el impacto de una situación médica inesperada es muy profundo y agudo. Se trata generalmente de familiares directos de personas jóvenes, que gozaban de un excelente estado de salud hasta hace pocos momentos, respecto de quien tienen que tomar la decisión de donar, o no, los órganos. Esto último, en un contexto cargado de prisas y presiones que se mezclan, precisamente, con el pronóstico ominoso de una persona que hasta hace pocas horas compartía plenamente con ellos. Se observa en la práctica que, más allá de directivas, voluntad anticipada expresada verbalmente en vida o presiones de diversa índole y origen, el equipo médico no extraerá ningún órgano del eventual donante, sin la autorización concreta y formal para ello. Justamente, creemos que no contribuye a una práctica de donación más generosa, entre otros factores, una cierta presión a la que se ven sometidos los familiares, precisamente en un momento muy triste e inesperado para ellos, en medio de múltiples rostros no familiares y personal del hospital que busca cumplir con directivas, programas, metas sanitarias, criterios de inclusión, urgencias de pacientes receptores y una larga lista de situaciones que distan mucho de promover una reflexión tranquila por parte de los familiares. Es quizás en estos momentos que el médico o profesional a cargo del paciente candidato a donar, aparte de comprender y entender con claridad los criterios para donar, sea el encargado de explicar en una forma delicada y humanitaria el significado que tiene la circunstancia por la que pasa su ser querido, y solicitar prudentemente un acto de donación libre y solidario, sin mezclarlo con aspectos legales y/o políticas sanitarias imperantes. Los argumentos legales, suelen no favorecer la toma de decisión por parte de la familia, más bien, son hasta cierto punto confundentes, especialmente en el momento que se vive.

La negación ante las donaciones, aun si la familia logró comprender su significado, se traduce en uno o más pacientes que seguirán a la espera de una solución a su enfermedad. Incluso en España, la negativa familiar es en torno al 15,9\%. En el Reino Unido, por ejemplo, la negativa familiar asciende a $41,4 \%$, Chile $48,9 \%$, Perú 63,6\% ó 47,2\% en Argentina ${ }^{11}$.

Otras consideraciones éticas del proceso donación-trasplante, se desprenden de los párrafos anteriores. Por ejemplo, en nuestro medio la escasez de órganos, los altos costos que demandan al sistema de salud, listas de espera y justa distribución de órganos. En una situación de intenso contenido biomédico, como la debatida, resulta éticamente mandatorio la correcta selección de los receptores de órganos, haciendo explícito y trasparente el principio de justicia distributiva.

Aunque no es motivo principal del presente 
trabajo, no podemos dejar de mencionar que también nos merece una reflexión el criterio de muerte encefálica, como definición de muerte del hombre, y que es utilizado para poder extraer órganos vitales del donante. Su sentido y valoración supera el ámbito de esta comunicación, pero baste mencionar que ya hay noticias de trasplante de corazón en Australia, en donante donde no se utilizó el criterio de muerte encefálica ${ }^{12}$.

Tampoco nos detendremos a analizar los dilemas que pueden presentar los xenotrasplantes, es decir, desde un animal a un ser humano u otros tipos de trasplantes, más allá de los problemas que se presentan en el proceso general de donacióntrasplante entre personas.

La condición que nos parece relevante de la donación de órganos, cualquiera que sea éste, es que sea realizada de forma altruista, sin saber a quién o quiénes irán a beneficiar los órganos donados. La belleza moral de la donación es la generosidad, que pretende como fin salvar la vida de otras personas, sin recibir nada a cambio. En nuestra opinión, pone de manifiesto una de las mejores características de una sociedad verdaderamente solidaria. Lamentablemente, y como es de público conocimiento, no alcanzan los órganos para todos los enfermos que lo requieren. Por el contrario, también debemos reconocer la triste e inmoral circunstancia de la compraventa de órganos, lo que se considera éticamente inaceptable, criterio que compartimos. Las instituciones internacionales han hecho recomendaciones contrarias a estas comercializaciones, y la OMS en el año 1991, ya estableció un principio rector contrario al comercio de órganos. En los países desarrollados esto no se lleva a cabo, pues hay unas normativas muy estrictas y se le considera un delito. No tenemos datos al respecto en nuestro país. Sin embargo, el "mito" del tráfico y/o comercialización ha causado que ciertas personas, ante el temor de que trafiquen con sus órganos, se nieguen a donarlos. "Bajo este nombre genérico se agrupan hechos reales y ficticios que ni conceptual ni técnicamente tienen casi nada en común, pero que han sido mezclados a veces de una forma irresponsable, fruto del desconocimiento. En otras ocasiones, en cambio, se ha hecho a sabiendas de la falsedad de lo que se estaba difundiendo en un claro ejemplo de autojustificación de los medios empleados en aras de un fin definido, aunque muchas veces inconfesable. Curiosamente, esta mezcla de hechos fácilmente demostrables, ficciones sin fundamento y rumores nunca confirmados, adoptando formas de pesadilla, ha pasado a formar parte del acervo cultural de la sociedad actual." 13 .
Por otra parte, para evitar que un sector de la población pueda pensar, que en base a su poder económico u otras influencias tiene mayor posibilidad de acceder a un órgano, es necesario cumplir verdaderamente con el principio de justicia distributiva, pues todos los enfermos son merecedores de recibir el órgano necesitado, al margen de su estatus económico o social. Por ello, cada vez más, los gobiernos luchan porque esta distribución de órganos sea equitativa, eficiente y transparente. En el caso de Chile, por ejemplo, para cumplir con estos criterios, existe una lista única de espera para los receptores, centralizada a nivel nacional.

Finalmente, no puede dejar de mencionarse que también existen criterios particulares y específicos en el mundo religioso respecto de esta técnica, pero no es motivo de este trabajo su examen en detalle.

\section{Bibliografía}

1.- SARRIAS X. Ética de los trasplantes. www.aceb. orghttp://www.aceb.org/traspl.htm (Consulta el 13 de noviembre de 2014).

2.- ÁlVAREZ J, SÁNCHEZ FRUCTUOSO A, DEL BARRIO M R, PRATS M D, TORRENTE M, ILLESCAS M L, MATEOS P, BARRIENTOS A. Donación de órganos a corazón parado. Resultados del Hospital Clínico San Carlos. Nefrología 1998; 18: (Supl 5): $47-$ 52.

3.- ANTÚNEZ M, CABELLO H, HOWARD M, SANTOLAYA R, MONTALBÁN C, BASCUÑÁN C. "Trasplante Pulmonar. Guías Clínicas. Sociedad Chilena de Trasplante". 2011 (Consulta el 11 de octubre de 2014). http://www.sociedaddetrasplante.cl/utilidades/biblioteca/category/22-capitulo-xi-trasplante-pulmonar.html\#>

4.- COLL E, SANTOS F, USSETTI P, CANELA M, BORROF J M, DE LA TORRE F M, et al. Registro Español de Trasplante Pulmonar: primer informe de resultados (2006-2010) Arch Bronconeumol 2013; 49: 70-8.

5.- CALVO V, PADILLA J, GARCÍA-ZARZA A, BLASCO E, PASTOR J, PARÍS F. Grupo de Trasplante Pulmonar de Valencia. El trasplante pulmonar en situación de urgencia. Arch Bronconeumol 2003; 39: 111-4.

6.- LÓPEZ-MESEGUER M, ROMÁN A, MONFORTE V, BRAVO C, SOLÉ J, MORELL F. Trasplante bipulmonar en hipertensión pulmonar. Una serie de 15 pacientes. Arch Bronconeumol 2009; 45: 366-70.

7.- Organización Nacional de trasplantes. Memoria de trasplante pulmonar. (Consulta el 13 de noviembre de 2014). http://www.ont.es/infesp/Memorias/Memoria\%20trasplante\%20pulmonar\%202013.pdf>

8.- Corporación Nacional de Fomento de Trasplante (Con- 
sulta el 20 de marzo de 2014). http://www.trasplante.cl/ nuestra-coporacion/biblioteca/category/3-resumenesanuales>

9.- Organización Nacional de Trasplante. (Consulta el 12 de noviembre de 2014) https://reports.ont.es/datoshistoricos.aspx

10.- http://www.trasplante.cl/nuestra-coporacion/biblioteca/ category/3-resumenes-anuales Ministerio de Salud, Gobierno de Chile. (Consulta el 16 de noviembre de 2014) http://web.minsal.cl/sites/default/files/trasplan- tes_noviembre.pdf

11.- International figures on donation and transplantation-2013. Newsletter Transplant, 2014 (Descargado el 11 de diciembre de 2014).

12.- http:/www.abc.es/salud/noticias/20141024/abci-trasplante-corazon-muerte-201410241524.html Publicado el 27 de octubre de 2014. (on line: 13 de diciembre de 2014).

13.- MATESANZ R. "Tráfico de órganos: hechos, ficciones y rumores” Nefrología 1994; 14: 633-45.

Correspondencia a:

Dr. Alberto Rojas O.

Facultad de Medicina

Universidad Andrés Bello

Sede Viña del Mar

Email: arojas1040@yahoo.com 